\title{
A educação física e moral dos corpos: Francisco de Mello Franco e a medicina luso-brasileira em fins do século XVIII
}

\author{
JEAN LUIZ NEVES ABREU*
}

\begin{abstract}
Resumo: O objetivo desse artigo é abordar o pensamento médico de Francisco de Mello Franco. O autor pode ser visto como um dos representantes da medicina luso-brasileira de fins do século XVIII, na medida em que incorpora não apenas as inovações do saber médico, como também aborda temas valorizados no período, como a moral, a educação física e a higiene dos corpos.

Abstract: The objective of this article is to approach the medical thought of Francisco de Mello Franco. The author can be seen as one of the representatives of the Luso-Brazilian medicine of ends of XVIII century, in the measure where he not only incorporates the innovations of medical knowledge, but also approaches subjects valued in that period, as the moral, the physical education and the hygiene of the bodies.
\end{abstract}

Palavras-chave: Moral. Educação física. Higiene.

Key words: Moral. Physical education. Hygiene.

\section{Introdução}

Durante grande parte do século XVIII a medicina lusobrasileira foi marcada pelas influências das concepções galênicas em que a doença era explicada pelo desequilíbrio dos humores. ${ }^{1}$ Ao

* Professor de História da UNIVALE-MG; doutorando (UFMG).

1 A então denominada "patologia humoral" retomava à concepção do corpo humano concebido como um microcosmo por conter dentro de si as qualidades dos quatro elementos da natureza. A partir dessa teoria, a regulação das três partes principais fígado, coração e cérebro - dependia do equilíbrio entre os quatro humores primários - sangue, cólera, fleuma e melancolia. As qualidades dos humores, por sua vez, eram estruturadas por pares de oposição: seco/úmido, frio/quente, delgado/grosso, doce/amargo; e as suas funções eram exercidas por relação de simpatia com determinados órgãos. CZERESNIA, Dina. Constituição epidêmica: velho e novo nas 
galenismo se entremeavam as concepções da enfermidade ligada ao sobrenatural e à magia. Embora tais aspectos não se limitassem à medicina portuguesa, o fato é que a cultura lusa se manteve relativamente fechada às inovações da ciência e do Iluminismo em voga em diversos países da Europa, o que se devia, principalmente, à influência da escolástica e da Igreja católica. ${ }^{2}$ Entretanto, desde meados do setecentos alguns setores da cultura letrada, ligados à Ilustração, não só criticavam o estado da medicina no Reino como propunham reformas sua renovação. Com a reforma dos Estatutos da Universidade de Coimbra, de 1772, o consulado pombalino criou uma atmosfera propícia à renovação dos estudos médicos, procurando rechaçar da medicina a influência do maravilhoso e difundir os preceitos racionalistas na arte médica. ${ }^{3}$

Francisco de Mello Franco foi um dos médicos que se formou no contexto de renovação dos estudos médicos em Portugal e cuja obra mereceu poucos estudos na historiografia brasileira. Em que medida as idéias desse autor permitem compreender as tendências da medicina luso-brasileira de fins do século XVIII? Quais os principais aspectos abordados nas obras desse autor? Esse artigo pretende apresentar algumas respostas a tais questões. Para tanto, além de abordar as concepções de medicina nas obras de Francisco de Mello Franco, pretende-se também analisar o contexto em que se insere a obra desse autor, trançando uma relação entre sua trajetória individual e a medicina de sua época.

\section{A formação de um médico}

Francisco de Mello Franco era natural de Paracatu, e foi, como era comum na época a muitos que desejavam obter formação superior, completar seus estudos em Portugal. Matriculou-se, em 1775, na Universidade de Coimbra em filosofia natural e medicina. Entretanto o curso fora interrompido pelo Santo Ofício que o man-

teorias e práticas da epidemiologia. História, ciências, saúde-Manguinhos, vol. VIII, julago, 2001, p. 342-344.

2 VILLALTA, Luiz Carlos. Reformismo ilustrado censura e práticas de leitura: usos do livro na América Portuguesa. Tese (doutorado em História) — Faculdade de Filosofia e Ciências Humanas, Universidade de São Paulo, 1999, p. 46-54.

3 Márcia Moisés Ribeiro desenvolveu esses aspectos em seu estudo sobre a arte médica no Brasil do século XVIII. Embora aponte algumas das mudanças ocorridas com a reforma da Universidade de Coimbra, essa autora conclui em seu estudo que as crenças próprias do universo mágico não desapareceram totalmente do pensamento das elites e que a convivência de velhos e novos paradigmas foi um dos aspectos da medicina em Portugal e no Brasil no século XVIII. RIBEIRO, Márcia Moisés. A ciência dos trópicos: a arte médica no Brasil do século XVIII. São Paulo: Hucitec, 1997, p. 131-140. 
teve preso entre 1777 e 1781, sendo acusado de herege, naturalista, dogmático, além de negar o matrimônio. Só retomou o curso em 1782, quando se viu livre da Inquisição, formando-se em 1785. Em Lisboa, dedicou-se à clínica e se tornou renomado médico, compondo inclusive a junta médica que examinou D. Maria I, declarando-a insana. Em 1817, veio para o Brasil na comitiva de D. Leopoldina da Áustria. Exerceu seu ofício na cidade do Rio de Janeiro, alcançando elevada reputação enquanto médico Nos momentos finais de sua vida foi alvo de intrigas palacianas, proibido de entrar na Corte por D. João VI, por acreditar que a intenção de Mello Franco era destitui-lo do poder. ${ }^{4}$ Pelas idéias que defendeu, o autor é inscrito por Antonio Candido no ciclo de protesto filosófico no Brasil, ligado ao círculo do pombalismo literário e conhecido pelas suas idéias avançadas. ${ }^{5}$ Como médico publicou diversas obras, Medicina teológica (1794), Tratado da educação fysica dos meninos, para uso da nação portuguesa (1790), Elementos de hygiene (1814) e Ensaio sobre as febres (1829).

Esses dados biográficos de Mello Franco já indicam sua inserção no pensamento Ilustrado, sendo o autor uma das vítimas do período da "viradeira" diante das reações de D. Maria I a letrados que se filiavam ao Marquês de Pombal. O poema satírico de autoria do autor que circulava em Coimbra, em 1785, O Reino da Estupidez, pode ser lido segundo Luiz Carlos Villalta, como uma "sátira poética à Universidade de Coimbra dos inícios da Viradeira" e representava as "inquietações da atmosfera literária coimbrã de meados dos anos 1780, os efeitos da Ilustração e as contradições do Reformismo Ilustrado português". 6 Dos vários aspectos abordados no poema satírico, tais como a crítica ao clero, à ignorância e às superstições, não ficam de fora as ciências e, em particular, os estudos anatômicos.

Histórias Naturais, Foronomias,

Químicas, Anatomias, e outros nomes,

Difíceis de reter, são as ciências,

Que vieram trazer os Estrangeiros.

Há cousa mais cruel, mais desumana

Mais contrária à razão, que ver os Médicos

Um cadáver humano espatifando,

Um corpo, que habitou o Espírito santo??

4 VILLALTA, op. cit., p. 165-166.

5 CANDIDO, Antonio. Formação da literatura brasileira. 1 - Momentos decisivos. Belo Horizonte: Rio de Janeiro: Itatiaia, 1987, p. 152-154.

6 VILLALTA, op. cit., p. 169.

7 FRANCO, Francisco de Mello. Reino da estupidez, poema. Hambourg, 1820, p. 35. 
Embora fosse uma reação à "Viradeira", a sátira de Mello Franco pode ser apropriada para situar as objeções que os "Ilustrados" faziam ao ensino livresco, à ignorância, à Inquisição e outros elementos que faziam de Portugal o reino da deusa Estupidez. No caso da medicina, Luís António Verney, clérigo português radicado na Itália, era um dos "estrangeirados" que se insurgiam contra os estudos médicos em Portugal. Diversas páginas do Verdadeiro método de estudar, obra em que escreveu criticando a influência da escolástica no ensino do Reino, eram dedicadas ao tema da medicina. Opunha-se o clérigo veementemente ao ensino livresco na medicina, o lugar consagrado às autoridades em lugar da prática, aspectos que não permitiam o médico conhecer o interior do corpo humano. Afirmava que os princípios galênicos eram prejudiciais aos estudos anatômicos, já que "ódio dos galênicos à anatomia provém dos princípios que beberam da filosofia peripatética. [...]. Assentam que a natureza é aquilo que leram nos seus livros; e ao depois, reduzem tudo o que observaram na natureza aos princípios que têm bebido. ${ }^{8}$

Outro apologista da ciência moderna e da renovação do ensino em Portugal foi o cristão-novo Antônio Ribeiro Sanches, que também viveu boa parte de sua vida fora de Portugal. Assim como Verney, ele considerava que o ensino da Universidade de Coimbra não oferecia condições para formarem profissionais necessários ao reino de Portugal, sobretudo médicos qualificados, pois "a Faculdade de medicina que existe em Coimbra é insuficiente para aprender o que necessita o naturalista, o físico, o químico, o médico e o anatomista. ${ }^{9}$

O discurso dos Ilustrados, contrário à tradição escolástica e à influência dos jesuítas no Reino - influência que, conforme se apregoava, atingia todo o conhecimento científico e não apenas a medicina - constituía o alicerce da peça que daria corpo aos novos Estatutos da Universidade de Coimbra, elaborado pela Junta da Providência Literária: o Compêndio Histórico do Estado da Universidade de Coimbra no Tempo da Invasão dos denominados jesuítas e dos estragos feitos nas Ciências. O documento, que pode ser considerado uma expressão da propaganda pombalina, denunciava a decadência e ruínas "em que as artes, as ciências foram precipitadas na Universidade de Coimbra pelas maquinações dos denominados jesuítas". ${ }^{10}$

8 VERNEY, Luís António. Verdadeiro método de estudar [1746].Vol. IV. Estudos médicos, jurídicos e teológicos. Lisboa: Livraria Sá da Costa, 1950, p. 24.

9 SANCHES, António Nunes Ribeiro. Cartas sobre a educação da mocidade, [1760]. Coimbra: Imprensa Universitária, 1922, p. 159.

10 Compêndio histórico do estado da Universidade de Coimbra no tempo da invasão dos denominados jesuítas. Lisboa: Na Régia Officina Typográfica, 1771, p. VII-VIII. 
Na peça apologética do Iluminismo Português já se assinalava não só a rejeição dos peripatéticos, como a valorização dos progressos das filosofias e físicas mecanicistas no tocante aos estudos médicos. Privilegiavam-se, assim, os princípios do mecanicismo em substituição aos da orientação livresca no estudo do corpo humano. Era o "espírito geométrico" e os sucessivos descobrimentos permitidos por este, que "deram um conhecimento mais perfeito do mecanismo do corpo". 11

No Compêndio histórico... se exaltavam as figuras de Harvey, Borelli, Boerhaave, entre outros médicos, cujos conhecimentos eram necessários para a renovação do saber médico. $\mathrm{O}$ documento apontava que durante muito tempo os estudos anatômicos foram impedidos pela "supertições do tempo sustentadas pelas leis públicas". No caso de Portugal, acusava os jesuítas, "maquinadores dos estatutos", pelo atraso dos estudos anatômicos e que embora os livros de Galeno oferecessem preciosas lições, por si só eram insuficientes, pleiteando a necessidade da dissecação nos cadáveres, sem a qual era impossível aprender a "conhecer a estrutura, a configuração, a conexão de qualquer parte do corpo humano como outras partes; mas também a fazer todas as operações próprias desta arte". 12

Os discursos que emergem das obras de Verney, Ribeiro Sanches e de diversos tratados médicos publicados posteriormente encontraria apoio não só na Junta da Providência Literária, como repercutia nos Estatutos da Universidade, elaborados a partir dos princípios científicos do Iluminismo e da ciência moderna na Europa. A reforma pombalina dos estudos superiores distribuiu a Universidade de Coimbra nas Faculdades de Teologia, Cânones, Leis, Medicina, Matemática e Filosofia. Aprovados em agosto de 1772, os Estatutos da Universidade dedicavam o terceiro capítulo à Faculdade de Medicina. Para cursar medicina, os estudantes deveriam ter certas habilitações, como o conhecimento do Latim, Grego e Filosofia. Em seguida, vinha o curso preparatório de três anos, durante o quais os alunos deveriam freqüentar as seguintes cadeiras: geometria e história natural no primeiro ano; cálculo e física experimental no segundo ano e foronomia - ciência completa dos movimentos - e química. No primeiro ano do curso, o aluno estudaria a matéria médica constituída pela história da medicina e o estudo das virtudes de diversas plantas e raízes. O segundo ano era dedicado inteiramente à anatomia com aulas práticas no hospi-

11 Idem, p. 337

12 Idem, p. 326. 
tal. O terceiro ano se ocupava das instituições médicas, em que os alunos aprendiam a medicina teórica, fisiologia, patologia, semiologia, higiene e terapêutica. No quarto ano se estudariam os aforismos de Hipócrates e Boerhaave e o quinto ano era dedicado inteiramente ao ensino clínico da medicina e à prática no hospital. ${ }^{13}$

Além de colocar em prática algumas idéias e contribuições de Verney e Ribeiro Sanches, Estatutos da Universidade de Coimbra dedicada à medicina evidencia a importância da história natural e o conhecimento da física e da química, necessárias ao verdadeiro conhecimento do corpo humano. Na esteira da relevância adquirida por essas disciplinas, está a valorização de nomes como Newton na física, Harvey na anatomia, Boerhaave em patologia e de Van Swieten em farmacologia, entre outros que renovaram os estudos da medicina européia. ${ }^{14}$

Os Estatutos determinavam ainda a construção de laboratórios e estabelecimentos para que os alunos pudessem colocar em prática as teorias. Para a prática da medicina e da cirurgia foi criado o Hospital Escolar, onde se situavam o teatro anatômico e o dispensário farmacêutico, que também deveria servir para a formação de boticários. Nesse mesmo espírito foram construídos outros estabelecimentos, como o observatório astronômico, um gabinete de história natural e de física experimental e um jardim botânico para ser utilizado pelos estudantes dos diversos cursos. Conforme sublinha Oswaldo Munteal Filho, os teatros, o laboratório químico, o museu de História Natural e demais estabelecimentos se efetivavam como centros de geração do conhecimento articulados pela reforma da Universidade. ${ }^{15}$

A reforma do ensino de medicina seguia a tendência da crítica à cultura livresca, evidenciando a valorização do experimentalismo e da prática. Enfatizava-se a relevância de se cultivar a "medicina empírico racional", na qual as luzes da teoria seriam úteis

13 PITA, João Rui. Medicina, cirurgia e arte farmacêutica na reforma pombalina da Universidade de Coimbra In: ARAÙJO, Ana Cristina (coord.). O marquês de Pombal e a universidade de Coimbra. Coimbra: Imprensa da Universidade, 2000, p. 129-162; GUERRA, João Pedro Miller. A reforma pombalina dos estudos médicos. In: CARVALHO DOS SANTOS, Maria Helena. Pombal revisitado. Vol. 1. Lisboa: Editorial Estampa, 1984, p. 189-208.

14 MAXWELL, Kenneth. Marquês de Pombal: paradoxo do iluminismo. Rio de Janeiro: Paz e Terra, 1996, p. 11.

15 MUNTEAL FILHO, Oswaldo. Domenico Vandelli no anfiteatro da natureza: a cultura científica do reformismo ilustrado português na crise do Antigo Sistema Colonial (1779-1808). Dissertação (Mestrado). Departamento de História, PUC - Rio de Janeiro, 1993, p. 60. 
para se poderem ler sem equivocação nas experiências as verdades que ensinam "o magistério da natureza"; e as "observações bem feitas, examinadas e comparadas, sirvam de retificar, verificar, ampliar, limitar, e aperfeiçoar os conhecimentos da teoria". ${ }^{16}$

Francisco de Mello Franco se formou, portanto, em um contexto de transformações do ensino médico em Portugal e se mostrava adepto de concepções de medicina que se difundiam em Portugal no período das reformas pombalinas. Dentre as teorias a que fazia referência em suas obras estava a do médico holandês Herman Boerhaave (1668-1738). Em Traité de la vertu des médicamens, Boerhaave defendia que "assim que o movimento dos líquidos se torna irregular, ou que ele cessa em qualquer parte que seja, o homem está doente, e assim que o movimento para em todo o corpo, o animal morre". ${ }^{17}$ Ao apoiar sua tese do equilíbrio da saúde nesses pressupostos, Boerhaave entendia que o corpo era como uma máquina, composto de tubulações feitas de canos e vasos que continham e canalizavam os líquidos corporais. A saúde era explicada mediante a circulação livre dos fluídos no sistema vascular, enquanto a doença era explicada em termos de bloqueio. A idéia do equilíbrio dos humores foi preservada, embora fosse traduzida em uma linguagem mecânica e hidrostática. ${ }^{18}$

Para explicar a digestão dos alimentos pelo organismo era a essas idéias que Francisco de Mello Franco se mostrava vincular. Segundo esse autor, o

homem não come nem bebe coisa alguma que não entra pelas vias da circulação: todas as comidas e bebidas são transformadas pela ação dos órgãos digestivos em um quilo que, misturado com nossos humores, lhes comunica as qualidades de que é dotado [...], porém, quando os órgãos digestivos estão fracos, tanto por inércia dos fluidos como por atonia dos sólidos, então o quilo não se neutraliza, mas se converte em ácido ou em alcalino, e vem a ser princípio de duas acrimônias, que por si só fazem grande estrago, mas que se curam muito bem uma por outra, isto é, o ácido pelo alcalino e o alcalino pelo sólido. 19

16 Estatutos ..., p. 18.

17 FERRAZ, Márcia Helena Mendes. As ciências em Portugal e no Brasil (1772-1822): o texto conflituoso da química. São Paulo: EDUC, 1997, p. 47.

18 PORTER, Roy. Das tripas coração: Uma breve história da medicina. Rio de Janeiro: Record, 2004, p. 88.

19 FRANCO, Francisco de Mello. Medicina teológica. São Paulo: Editora Giordano, 1994, p. 86-87. 
Ao se mostrar familiarizado com as teorias de Boerhaave, Francisco de Mello Franco acabava por incorporar também os preceitos do mecanicismo e os aplicar à medicina para explicar o funcionamento do corpo humano. Defendendo o monopólio do conhecimento do corpo humano pelos médicos, Francisco de Mello Franco insurgia-se contra os teólogos, afirmando que o homem era uma "máquina visível", que "só o médico tem dela um conhecimento mais profundo". 20

A concepção do corpo como uma "máquina visível" era, desde o século XVII, uma das bases dos estudos de medicina e, particularmente, de anatomia. Ao propor a idéia da máquina como modelo do corpo humano, a filosofia mecanicista procurava edificar uma nova imagem do corpo humano. A idéia do mecanismo era, portanto, bastante elástica para comportar diversas comparações entre os mecanismos e o corpo humano: os relógios, chafarizes e moinhos eram mecanismos equiparados ao corpo e a compreensão desse mecanismo, que podia ser desmontado devido ao avanço da anatomia, revelava aos médicos, não mais uma unidade, mas um corpo fragmentado, constituído de órgãos e ossos. ${ }^{21}$

A concepção do corpo-máquina, à qual se vinculavam os médicos na Holanda, França, Itália, entre outros locais da Europa desde o século XVII, foi incorporada pelos médicos portugueses no decurso do setecentos, em particular pelos "estrangeirados" e por aqueles que se opunham à medicina de tendência galênica. Em acordo com essas concepções, Verney afirmava que o "nosso corpo é uma máquina hidráulica muito mais perfeita que um relógio; pois nele vemos os vasos e fluidos que correm por eles, e os ossos, que sustentam toda a máquina". 22

Francisco de Mello Franco não só revela ser partidário dos princípios mecanicistas acima mencionados, como também aprofunda aspectos da neurologia. Para esse autor, eram os nervos que explicavam os movimentos do corpo humano e a comunicação entre o cérebro e o corpo:

20 Franco, Medicina...., p. 21.

21 Diversos são os autores que abordam a concepção mecanicista do corpo humano. Sobre a filosofia mecanicista e a metáfora do corpo-máquina ver, entre outros: ROSSI, Paolo. O nascimento da ciência moderna na Europa.São Paulo: Edusc, 2001, p. 246257; MANDRESSI, Rafael. Dissections et anatomie. In: VIGARELLO, Georges (dir.). Histoire $d u$ corps. De la Renaissance aux Lumières. Paris: Éditions du Seuil, 2005, p. 331-333.

22 VERNEY, op. cit., p. 13. 
os nervos são uns cordões que tomam sua origem do cérebro e da medula espinal, que se distribuem por todas as partes do corpo. Pouco custa saber que os nervos parecem ser prolongamentos da substância medular de onde vêm e que a sua força, igualmente que sua firmeza, se devem às membranas ou túnicas em que estão envolvidos; como também que estes nervos, ou sejam grossos ou sejam finos, são compostos de muitos fios que correm sempre com distinção uns dos outros e se podem chamar nervos multiplicados. ${ }^{23}$

Pelas idéias que propõe, o médico envereda pela análise das sensações do indivíduo, transformando a teologia moral em psicologia médica. ${ }^{24} \mathrm{O}$ conhecimento do funcionamento dos nervos disponível à época tornava possível explicar as ações humanas e suas "paixões" em termos médicos. A alma, termo associado à religião, passava a ser objeto do saber médico, sendo atribuída a ela as sensações do corpo humano. Era sob esse prisma que Ribeiro Sanches, antes de Francisco de Mello Franco, abordava a questão, afirmando que trataria das "paixões da alma como causa de muitas doenças e enfermidades, o que pertence essencialmente à Patologia". Para sustentar suas opiniões, Ribeiro Sanches recorria aos conhecimentos de anatomia, que permitia ao médico adentrar no "mais profundo e oculto do corpo humano" e descobrir os nervos:

E para que tenhamos deste corpo sensiente e movente uma idéia mais completa, separe [...] o coração com todas as artérias que saem dele com a sua continuação que são as veias e que vêm por dois canais acabar no coração direito [...] o vazio que haverá entre estas artérias e veias o ocupavam os nervos. ${ }^{25}$

Ao compartilhar de princípios semelhantes, Mello Franco não apenas se mostra vinculado ao Iluminismo médico português, como também se filiava à vertente do pensamento ilustrado que colocava em xeque a autoridade da Igreja nos assuntos médicos, como se propõe mostrar a seguir.

23 Idem, p. 31-32.

24 MASSIMI, Marina. As idéias psicológicas de Francisco de Mello Franco, médico e iluminista brasileiro. Psicologia: teoria e pesquisa, Brasília, 7 (1), p. 84-86, 1991, p. 87.

25 SANCHES, António Ribeiro. Dissertação sobre as paixões da alma. Covilhã-Portugal: Universidade de Beira Interior, 2003, p. 1-2. 


\section{Da teologia à medicina: as enfermidades do amor}

As considerações acerca da máquina do corpo humano e da neurologia eram expressas por Francisco de Mello Franco na sua obra Medicina teológica. Este livro foi publicado anonimamente em 1794 e recolhido um mês depois pelo Intendente Geral de Polícia, Pina Manique, que considerou a obra "perigosa e heterodoxa" e procurou, em vão, identificar o autor de tão afamado compêndio. ${ }^{26}$

O que afinal teria levado Medicina teológica a ser considerada obra tão perigosa? Esse aspecto não deve ser atribuído, a nosso ver, pela defesa do corpo como uma máquina. Afinal, naquele período, inúmeros eram os médicos que defendiam tais posições. A controvérsias suscitadas pela obra se devem ao fato de que em várias passagens seu autor se insurgia contra os domínios dos eclesiásticos sobre a medicina.

Durante muito tempo, a medicina foi, em Portugal e na América Portuguesa, uma aliada da religião. Brás Luís de Abreu, cuja obra foi publicada em 1726, era um dos muitos médicos portugueses que defendiam a aliança entre a medicina e a religião e compartilhava da crença de que Deus podia curar as doenças. Referindo-se aos milagres narrados na Bíblia, esse afirmava que "Cristo nosso bem, também foi o verdadeiro médico, que nos livrou de todo o mal [...], ele curou leprosos, paralíticos, lunáticos, licantrópicos, cegos, mudos, surdos, febricitantes, hidrópicos e tísicos". ${ }^{27}$ A forte presença da Igreja na sociedade portuguesa é um dos elementos explicativos para se compreender não só a influência da teologia na medicina, como também o uso de remédios divinos: água benta, imagens religiosas, promessas, culto aos santos, relíquias, e exorcismos, sendo esses remédios receitados por diversos médicos. ${ }^{28}$

Embora o título da obra de Mello Franco, Medicina teológica, possa aludir às relações de proximidade entre a medicina e a religião em fins do século XVIII e ele próprio afirmar que medicina e teologia eram tão ligadas que "nunca andassem uma da outra separadas" 29 , apesar disso, diversos aspectos da obra indicam uma tentativa de separar o campo de atuação do médico do teólogo. É o que se evidencia no fato de que na obra o autor analisa os males provocados pelo amor enquanto doença, afastando-se da idéia teológica que vê a luxúria enquanto pecado.

26 VILLALTA, op. cit., p. 199.

27 ABREU, Brás Luís de. Portugal médico ou monarchia medico-lusitana: Coimbra: Joam Antunes, 1726, p. 243.

28 RIBEIRO, Márcia Moisés. Exorcistas e demônios: demonologia e exorcismos no mundo luso brasileiro. Rio de Janeiro: Campus, 2003, p. 70-78.

29 FRANCO, Medicina..., p. 21. 
Primeiramente, é possível observar que o autor não apenas torna patológico o amor humano, mas também o divino. A Escritura Santa estava cheia de exemplos que "provam a languidez e a desfalência, que em muitas almas pias produziu o amor divino". 30

O amor como doença se aplica não apenas à fixação ao homem ou a uma mulher, mas a qualquer objeto amado, como o ouro e os livros. O processo que leva o amor a se transformar em uma enfermidade se dá "pela decomposição das fibras nervosas". Com base nas concepções dos sólidos e líquidos de Boerhaave, o autor considera que o amor perverte "os fluidos mais principais do corpo". ${ }^{31}$ Conforme se percebe, Mello Franco não associa o amor a um pecado, mas uma enfermidade provocada pelas fibras nervosas. Além do mais, o autor compartilha da idéia do corpo "máquina", que infeccionada pelo amor leva a uma derrocada do sistema nervoso.

Além de defender que a origem das enfermidades se encontrava no corpo humano e explicar as doenças "morais" através das paixões que "descompõem a fábrica interior do cérebro"32, Francisco de Mello Franco tecia críticas aos remédios receitados pela Igreja para controlar os excessos da carne, tais como a satiríase e furor uterino:

O evangelho manda mortificar nossos corpos, fazê-los vítima da penitência; e os santos se maltratavam com jejuns, cilícios, açoites, até se fazerem chagas vivas, derramarem muito sangue e mesmo desfalecerem no meio de seus tormentos solitários [...]. Ora, tudo isto estraga a saúde do corpo, encurta a vida. ${ }^{33}$

Aos rigores dos açoites e castigos prescritos pela Igreja, o médico indicava aos "senhores confessores" os remédios antiafrodisíacos: a sangria, banhos, purgantes, anti-sépticos e as bebidas refrigerantes. Receitava ainda algumas drogas específicas para frear o estímulo da lascívia, tais como a cânfora, a arruda, a hortelã, entre outras com a mesma finalidade. 34

A receita de remédios físicos para as enfermidades provocadas pelo amor se coaduna com a perspectiva médica do Iluminismo, para o qual as paixões provocavam efeitos mórbidos sobre o corpo. O pensamento de Francisco de Mello Franco se afina, assim, com a perspectiva da Enciclopédia, onde se considera que a "loucura do amor" provoca desordens na "economia animal". Para uma doença tão perigosa, os remédios morais não são de "nenhum socorro". Somente a farmácia pode fornecer os meios necessários para devolver

30 Idem, p. 39.

31 FRANCO, Medicina..., p. 41-42.

32 Idem, p. 41.

33 Idem, p. 95-96.

34 Idem, p. 108-111. 
a paz de espírito, apaziguando a agitação dos humores: "tais são os refrigerantes, os edulcorantes, como o leite, as emulsões de sementes frias, as tisanas apropriadas, os banhos, os anódicos". ${ }^{35}$

Ao se ancorar nos princípios análogos aos da Enciclopédia, Francisco de Mello Franco se afastava da perspectiva eclesiástica, que defendia o uso de remédios morais. Endereçando sua obra "aos senhores confessores" propunha, de certa forma, a supremacia dos remédios físicos e do utilitarismo médico no controle dos corpos. Duvidava ainda da conduta moral dos religiosos que só buscavam a cura das paixões apenas no ascetismo religioso. Embora acreditasse em uma indissociabilidade entre alma e corpo, pois a "alma obra no corpo e o corpo na alma", 36 esclarecia que as causas das enfermidades da alma eram todas corporais, pois, "ou no corpo têm assento ou dele dependem; logo devem ser corporais os remédios". ${ }^{37}$ Duvidava, por fim, do valor das penitências e das lições da Igreja, insuficientes para combater os males do amor.

Os mesmos eclesiásticos, os clérigos, frades e freiras que deviam ocupar-se continuamente na lição santa da teologia ascética, moral e dogmática, nem ter outra vida que a de um contínuo recurso à oração e à penitência, quais são de entre eles que assim o praticam e assim vivem? 38

Além do ataque ao modo de vida do clero, tais preposições e idéias sustentadas por esse médico rompiam com a idéia de que a medicina deveria ser submissa à religião. Mello Franco se colocava, portanto, em relativa distância das idéias defendidas em tratados de medicina anteriores, como o Portugal médico... de Brás Luís de Abreu, publicado em um período anterior às reformas pombalinas. Nesse aspecto, há que se concordar com Henrique Carneiro, para o qual a defesa do "recurso médico materialista da droga como remédio contra o pecado é o que fez o livro de Mello Franco ser considerado tão ofensivo à Igreja". ${ }^{39}$ Medicina teológica indica, assim, os domínios do saber médico sobre a moral. A obra revela, nesse sentido, como em fins do século XVIII a medicina procurava lançar mão dos remédios para combater os males atribuídos às enfermidades do amor.

35 CARNEIRO, Henrique. Amores e sonhos da flora: afrodisíacos e alucinógenos na botânica e na farmácia. São Paulo: Xamã, 2002, p. 119-120.

36 FRANCO, Medicina..., p. 15.

37 Idem, p. 22

38 Idem,, p. 106

39 CARNEIRO, op. cit., p. 26. 
Tal hipótese se consolida se atentarmos para o fato de que Medicina teológica foi objeto não só de perseguição da polícia, como também de objeto de réplica. Em resposta à obra do médico, Frei Manoel de Santa Ana publicou, em 1799, um compêndio intitulado Dissertações teológicas medicinais, dirigidas á instrução dos penitentes, que no sacramento da penitência sinceramente procurarão a sua santificação, para que não contaminem como os abomináveis erros de um livro intitulado: medicina teológica. Pelo título já se observa a intenção em colocar abaixo as posições de Mello Franco, pois este havia lançado ridículos sobre as idéias teológico-morais. $\mathrm{O}$ frei defendia que, ao contrário do que supunha o médico, os males da alma se curavam com a graça divina e não com a medicina. 40

As idéias de Mello Franco mostram as fissuras nas relações entre a religião e o saber médico de fins do século XVIII, o que não significa que o discurso médico prescindisse de uma concepção de moral. A perspectiva adotada pelo médico não deve ser vista como isolada. Na passagem do século XVIII para o XIX, o campo da moral ia migrar cada vez mais para a medicina que se desvincularia da idéia do amor como um pecado. Com esse autor, a meu ver, temos, de certa forma, os alicerces da "medicina moral" no Brasil. Esse conceito, conforme propõe Jurandir Freire Costa, diz respeito à especialidade médica que teria direito sobre a moral privada e pública dos indivíduos, em que ocorre um deslocamento da moral do campo religioso para o biológico, em que o amor passa a ser reduzido a um fenômeno manejável pelas técnicas médicas. ${ }^{41}$ Conforme observa Henrique Carneiro, a "patologização do amor se refinará no século XIX quando uma longa série de doenças serão atribuídas à libertinagem e aos excessos venéreos", levando a uma invasão do "domínio amoroso pela medicina prescritiva, moralista e normatizadora". 42

Ao conduzir o amor ao espaço do corpo e do olhar dos médicos, Francisco de Mello Franco anuncia os novos tempos do discurso higienista, sem deixar de se ancorar e dialogar com o passado. Esse processo de modificação do estatuto das enfermidades e da própria dimensão da moral não se circunscreve apenas ao âmbito da sexualidade, na medida em que medicina - ainda que tal perspectiva se assuma timidamente em meio aos preceitos cristãos

40 LUCAS, Fábio. Ousadias terapêuticas do Dr. Francisco de Mello Franco In: Luzes e trevas: Minas Gerais no século XVIII. Belo Horizonte: Editora UFMG, 1998, p. 98-99.

41 Para a diferença entre moral religiosa e médica ver: COSTA, Jurandir Freire. Ordem médica e norma familiar. Rio de Janeiro: Edições Graal, 2004, p. 64-65.

42 CARNEIRO, Henrique. A Igreja, a medicina e o amor: prédicas moralistas da época moderna em Portugal e no Brasil. São Paulo: Xamã, 2000, p. 50. 
- procurava uma reforma profunda do corpo, que perpassa não apenas pelas concepções acerca da enfermidade, mas também pela valorização da higiene, da medicina voltada para a família e da educação do corpo.

\section{A educação física e moral do corpo}

Se Medicina teológica foi obra controversa, provocando reações repressoras, Tratado de Educação Fysica para os meninos da nação portuguesa, publicado em 1790, merece destaque enquanto obra que trata de um tema em voga na medicina de final do setecentos: os cuidados relativos à criação das crianças. Embora já houvesse uma literatura dedicada ao tema, como é o caso da publicada pelo jesuíta Alexandre de Gusmão, Arte de criar bem os filhos na idade da puerícia, de 1685 , eram poucos os tratados escritos por médicos dedicados ao tema da infância. Um dos textos médicos em que o tema vem à baila é de autoria de Francisco da Fonseca Henriquez, que em Medicina lusitana dedicava uma parte do livro à "arte de criar e curar os meninos desde que nascem até serem adultos". Nessa obra publicada nas primeiras décadas do século XVIII, o médico insistia na importância de uma série de cuidados relacionados à criação das crianças. ${ }^{43} \mathrm{Em}$ bora demonstrasse preocupação com a infância, o tema aparece em meio a tantas outras questões que Francisco da Fonseca Henriquez abordava. É somente em fins do século XVIII que aparecerá uma literatura médica dedicada especificamente à infância e, de forma correlata, à família. Dessa forma, as crianças mereceram um maior investimento da medicina, o que correspondia não só a uma maior intervenção do médico nas famílias, como também à necessidade de melhorar o estado sanitário da população. ${ }^{44}$

A obra de Francisco de Mello Franco participa, portanto, desse processo em que a medicina passa a exercer cada vez mais um papel pedagógico, procurando prescrever formas de garantir a saúde da população. ${ }^{45}$ Em Tratado de educação fysica... diversos são

43 HENRIQUEZ, Francisco da Fonseca. Medicina lusitana: socorro delfhico aos clamores da natureza humana. Lisboa: Miguel Diaz, 1721, p. 156.

44 FERREIRA, António Gomes. A infância no discurso dos intelectuais portugueses do Antigo Regime. In: FREITAS, Marcos Cezar de; KUHLMANN JR, Moysés. Os intelectuais na história da infância. São Paulo: Cortez, 2002, p. 191.

45 Sobre a medicina de cunho preventivo que circulava em Portugal e na América Portuguesa ver o artigo de: MARQUES, Vera Regina Beltrão. Instruir para fazer a ciência e a medicina chegar ao povo no Setecentos. Varia História. Departamento de História, Programa de Pós-Graduação em História, Faculdade de Filosofia e Ciências Humanas, Universidade Federal de Minas Gerais, Belo Horizonte, n. 32, p. 37-47, 2004. 
os conselhos dados não só à melhor forma de criar as crianças, mas também ao cuidado que se devia ter com a saúde dos pais. Em uma sociedade em que eram comuns casamentos entre homens mais velhos e mulheres jovens ${ }^{46}$, Francisco de Mello Franco considerava ser "barbaridade sacrificar uma menina de 12 ou 14 anos nas mãos de um velho de 60 , ou 70 anos, e às vezes mais idade". ${ }^{47}$

Ao se posicionar contrário a esses costumes, o médico se mostraria afinado com a perspectiva da medicina higienista que iria se consolidar no Brasil do século XIX, defensora daquilo que Jurandir Freire Costa definiu de "amor higiênico", em que o que se levava em consideração era a saúde dos corpos. Dessa forma, o casamento das mulheres novas era considerado impróprio, já que não possuíam o organismo desenvolvido para a gestação. ${ }^{48}$ Tais conselhos se estendiam também aos cuidados com o vestuário correto a ser utilizado durante a gravidez, desaconselhandose o uso de vestidos ou cintas que apertassem o ventre. Havia a noção de que a mulher no estado de gravidez era muito sensível e que essas roupas influenciavam "na sua máquina o novo estado do útero". 49

Uma outra questão abordada nessa obra de Mello Franco diz respeito à amamentação. $\mathrm{O}$ autor propunha o uso da mamadeira como sucessor do aleitamento materno, descrevendo o instrumento como o "mais aperfeiçoado".50 A literatura médica do período via uma grande relevância nos cuidados com a alimentação das crianças pequenas, sobretudo no que diz respeito à amamentação materna, já que se considerava que os hábitos e costumes das mães se transmitiam aos filhos. Daí o fato de que os cuidados físicos com as crianças deveriam refletir a boa constituição fisiológica materna. ${ }^{51}$

Ligado a essa perspectiva havia a idéia de que o corpo da criança era uma página em branco e que, sendo assim, poderia ser moldado. Esse pensamento traduz a assimilação do novo pedagógico acerca da infância em Portugal, ancorado, sobretudo, no pensamento de John Locke. Este autor tinha exercido uma grande in-

46 FREYRE, Gilberto. Casa-grande e senzala: formação da família brasileira sob o regime patriarcal. $49^{a}$ ed. São Paulo: Global Editora, 2004, p. 429-432.

47 FRANCO, Francisco de Mello. Tratado de educação fysica dos meninos, para uso da nação portuguesa. Lisboa: Officina da Academia Real das Sciencias de Lisboa, 1790, p. 3.

48 COSTA, op. cit., p. 220.

49 FRANCO, Tratado..., p. 5.

50 Idem., p. 159.

51 DEL PRIORE, Mary. Ao sul do corpo: condição feminina, maternidades e mentalidades no Brasil Colônia. Rio de Janeiro: José Olympio, 1995, p. 169. 
fluência no pensamento pedagógico do século XVIII, já que sua obra Da educação das crianças, publicada em Londres em 1693 e traduzido para o francês em 1695, enfatizava a importância da prevenção como o meio mais eficaz para preservar a saúde dos filhos. 52

Era com base nesse pensamento preventivo que Francisco de Mello Franco defendia a ação transformadora do exercício físico desde a tenra infância. Estes eram recomendados de acordo com a idade e compreendiam desde a educação literária e as brincadeiras na infância. Na puberdade devia-se aprender a nadar nos rios e no mar. "O esgrimir as armas também devia entrar no plano da boa educação física. Com este exercício os membros se vigoram, e ganham força incrível nos músculos dos braços e pernas", dizia o médico. $53 \mathrm{O}$ exercício possuía diversas utilidades, agindo sobre a máquina do corpo humano. "Agita-se pois a circulação; promovem-se as secreções, e excreções; corroboram-se os sólidos, e estabelece-se o equilíbrio nas diferentes funções de cada um dos órgãos, que compõem a nossa máquina". Era o que afirmava Mello Franco em obra publicada no século XIX, Elementos de Hygiene. ${ }^{54}$

É fato que a valorização do exercício físico não é algo que deve ser creditado apenas aos tratados médicos de fins do século XVIII. Em obras anteriores os exercícios físicos eram considerados como um componente importante. No entanto, ele se prestava principalmente à conservação da saúde. Nesse caso os médicos, sobretudo aqueles que se ancoravam na perspectiva da medicina galênica, defendiam a necessidade de descanso e exercícios moderados. É o caso de Fonseca Henriquez, que atacava o ócio e a preguiça já que podiam ser muito prejudiciais: "faltando o movimento e exercício do corpo, não faltarão achaques que acabem a vida, ou a façam morbosa, porque o corpo irá se enchendo dos excrementos e superfluidades que o exercício havia de gastar", ${ }^{5}$ Médicos como Francisco Henriquez, no entanto, não atribuem ao exercício físico uma ação transformadora sobre o corpo, pois o "grande exercícios

52 Sobre a importância da obra de Locke ver, entre outros, GÈLIS, Jacques. A individualização da criança. In: CHARTIER, Roger; ARIÈS, Philippe. História da vida privada. 3 - Da Renascença ao século das Luzes. São Paulo: Companhia das Letras, 1991, p. 301.

53 FRANCO, Tratado..., p. 93-94.

54 FRANCO, Francisco de Mello. Elementos de hygiene ou dictames theoreticos, e practicos para conservar a saúde e prolongar a vida. Lisboa: Typografia da Academia, 1823 (Edição Fac-Símile, 2004), p. 235.

55 HENRIQUEZ, Francisco da Fonseca. Âncora medicinal para conservar a vida com saúde [1721]. São Paulo: Ateliê Editorial, 2004, p. 278. 
e o trabalho continuado [...] gastam as forças, enfraquecem as juntas e todo o sistema nervoso, debilitam o calor natural". ${ }^{56}$

$\mathrm{O}$ que mudou entre a perspectiva de Fonseca Henriquez e Mello Franco foi a influência que o último teve das concepções mecanicistas e dos desdobramentos dos estudos anatômicos. Podemos sustentar, nesse caso, a hipótese defendida por Georges Vigarello, para quem a transformação da compreensão do movimento gestual foi marcada por um lento abandono da referência aos humores e pela insistência cada vez maior sobre a importância das fibras e nervos na constituição física, bem como uma presença maior do exame dos princípios fisiológicos e anatômicos no exame do corpo. ${ }^{57}$

Havia, então, uma relação intrínseca entre os conselhos sobre os exercícios físicos e os estudos anatômicos. Os médicos de fins do Setecentos não pensavam o exercício mais no âmbito do equilíbrio ou purgação dos humores. Ainda que se referissem a esses princípios, concebiam o corpo como uma máquina, a exemplo de Francisco José de Almeida, que ao escrever seu tratado de educação física com título homônimo à obra de Mello Franco, via também o corpo como uma "máquina hidráulica". 58 Entre os inúmeros autores estrangeiros com livros traduzidos no Reino que poderiam fornecer esses argumentos aos médicos portugueses, pode-se citar Guilherme Buchan. Partindo da concepção do corpo enquanto uma máquina, defendia o uso do exercício para mover as partes da "economia animal", "sem o auxílio do qual não podem ser perfeitas a circulação do sangue, nem as secreções, tão pouco preparar-se os humores, nem adquirir firmeza os líquidos, e força os sólidos". ${ }^{59}$

O mecanicismo passava a oferecer o rol dos argumentos para a defesa das atividades físicas. Nesse sentido, valorizavam-se aqueles exercícios que endureciam o corpo ou que dele exigiam força, como era a esgrima, a equitação e a natação. Se por um lado, a relação entre as atividades físicas e o vigor do corpo era alicerçada por transformações teóricas do saber médico; por outro, o modelo estético que se aspirava para esses corpos era fornecido pela Antiguidade greco-romana. Ao lançar os olhos para as "formosas estátuas" da Antiguidade, as quais escapavam à "voracidade do

56 Idem, p. 277

57 VIGARELLO, Georges. S'exercer, jouer. In: VIGARELLO, Georges (dir.) Histoire du corps. De la Renaissance aux Lumières. Paris: Éditions du Seuil, 2005, p. 287,

58 ALMEIDA, Francisco José. Tratado de educação fysica dos meninos para uso da nação Portuguesa Lisboa: Na officina da Academia Real de Ciências, 1791, p. 15.

59 BUCHAN, Guilherme. Medicina domestica ou tratado completo dos meios de conservar a saúde e de curar. Lisboa: Typografia Rollandiana, 1788, v. 1, p. 80. 
tempo", Francisco de Mello Franco atestava que "todas tem espáduas mais largas, os braços mais grossos, as pernas musculosas". ${ }^{60}$ A idealização do vigor no cidadão antigo em pleno século das Luzes expressava a defesa dos costumes simples contra a corrupção, a regeneração do corpo contra a decadência. ${ }^{61}$

A condenação aos artifícios de uma sociedade viciada pelo luxo repercutia diretamente na concepção de educação física no século XVIII. Os próprios homens viviam uma vida ociosa que produziam um corpo enfraquecido, e os exercícios representavam uma das formas de luta contra os hábitos que tinham levado à degeneração dos corpos. ${ }^{62}$ Além das referências dos moralistas ao ócio e seus perigos, outras razões impediam o fortalecimento do corpo. Mello Franco condenava a invenção das armas de fogo, já que a invenção da pólvora acarretou o desprezo da ginástica e dos jogos militares. Os exércitos profissionais levaram muitos homens a uma vida "mole, afeminada, engolfada nos deleites, nos jogos". .63

A idéia de que a educação física era a solução não só para preparar as crianças para os rigores da vida, mas também uma medida para livrar os homens da indolência em que viviam, seriam aspectos retomados em Elementos de hygiene, onde Mello Franco se referia ao Brasil e da importância de aí se introduzir os exercícios como medida preventiva para a mocidade garantir a saúde.

Lembremo-nos por esta ocasião, que no Brasil principalmente nos portos do mar, é de necessidade introduzir todas as qualidades de exercícios varonis, com os quais aqueles habitantes frouxos e valetudinários já pelo clima, e já por hábito de indolência se fizessem vigorosos desde a sua mocidade. 64

\section{A higiene: fortalecedora do corpo, contra os miasmas e a favor da moral}

Outro tema presente nas obras de Francisco de Mello Franco que explicita o aspecto preventivo do saber médico em fins do século XVIII é o da higiene, vista não apenas como uma forma de limpeza, mas também de fortalecer o corpo. Nesse aspecto, é significativa a posição acerca dos banhos frios que deveriam ser dados às crianças. Com base nos estudos anatômicos, Francisco de Mello

60 FRANCO, Tratado...,p. 27-28.

61 VIGARELLO, op. cit., p. 134.

62 CRESPO, Jorge. A história do corpo. Lisboa: DIFEL, 1990, p. 558.

63 FRANCO, Tratado..., p. 28.

64 FRANCO, Elementos..., p. 248-249. 
Franco analisava que o fato dos meninos apresentarem a fibra mole, frouxa e quase sem ação e que os banhos de água morna lhes aumentava a languidez e inércia. Os banhos mornos e quentes só se justificavam nos primeiros dias de vida, passando-se logo aos banhos frios, que "seguramente emendam aqueles defeitos inseparáveis da sua primeira organização". ${ }^{65}$ Incorporando os mesmos pressupostos, Francisco José de Almeida desaconselhava igualmente os banhos quentes, já que este afrouxava as fibras, e "enfraquecendo os nervos vai de encontro ao trabalho da natureza, e debilita a constituição mais vigorosa". ${ }^{66} \mathrm{O}$ banho frio era responsável, portanto, pelo novo vigor do corpo, tornando os homens mais fortes e mais robustos. Sobre a eficácia do banho frio no século XVIII, Vigarello sublinhou que mais do que uma simples prática de higiene, o "que conta é a ação sobre a máquina orgânica, antes mesmo da ação sobre a limpeza da pele". Dessa forma, a "água é sempre confrontada com os funcionamentos do corpo". ${ }^{67}$

Outros conselhos do médico sobre a higiene se voltavam para as preocupações acerca dos miasmas corruptos que a atmosfera possuía. Nesse sentido, Mello Franco estava a par também das teorias dos contágios pelo ar da Europa das Luzes, atribuindo-se ao ar impuro a constituição de diversas enfermidades. ${ }^{68} \mathrm{~A}$ partir das idéias sobre os efeitos do ar nos corpos, na obra Medicina teológica Mello Franco solicitava aos confessores que aconselhassem aos penitentes que vivessem longe da cidade e que trabalhassem ao ar livre evitando as ruas infames e que não fossem "às casas das meretrizes e do jogo, às tabernas e outros lugares onde fisicamente se respira um ar pestilento ou infeccionado com exalações que se levantam dos corpos minados de doenças". ${ }^{69}$

A afirmação indica que os argumentos acerca da higiene não estavam dissociados de uma perspectiva moral. $\mathrm{O}$ ar exalado pelos corpos em lugares fechados, como os das prostitutas, era passível de contaminar as pessoas, o que levava a se considerar essas mulheres perigosas. ${ }^{70} \mathrm{O}$ ar que os corpos exalavam e tomavam conta da atmosfera se manifestava "mais particularmente nas pessoas débeis e delicadas, as quais continuando a estar nele, muitas vezes

\footnotetext{
65 FRANCO, Tratado..., p. 22.

66 ALMEIDA, op. cit., p. 27.

67 VIGARELLO, Georges. O limpo e o sujo: uma história da higiene corpora. São Paulo: Ática, 1996, p. 130-131.

68 Sobre esse aspecto, consultar CORBIN, Alain. Saberes e odores: o olfato e o imaginário social nos séculos dezoito e dezenove. São Paulo: Companhia das Letras, 1987.

69 FRANCO, Medicina..., p. 138.

70 CORBIN, op. cit., especificamente o capítulo 3: "Emanações sociais", p. 51-78.
} 
cai em asfixia”. Dessa forma, para além da alteração do ar, os lugares fechados emanavam os miasmas, os quais, "atacando os nervos, tendem a aniquilar a vida". 71

Diante dos limites disponíveis para um artigo, procurou-se abordar de forma concisa as principais idéias e perspectivas de Francisco de Mello Franco. Dos aspectos abordados, cabe ressaltar que o autor se mostrava em sintonia com as inovações médicas de fins do século XVIII, podendo sua obra ser considerada uma tendência da medicina do período. É a partir das matrizes teóricas acerca da enfermidade e do corpo fornecidas em grande parte pelo mecanicismo, que o médico forja suas perspectivas acerca da saúde, dos remédios e da higiene. Dessa forma, temas já abordados em tratados médicos publicados anteriores às obras de Mello Franco, ganham novas interpretações, como é o caso da utilização dos remédios físicos para combater as enfermidades da alma e o valor dado à educação física na ação transformadora dos corpos. O pensamento médico de fins do século XVIII dá assim uma nova dimensão à moral e à constituição física do homem. Apesar disso, esse pensamento não se afirma sem controvérsias, levando Francisco de Mello Franco a pagar caro por algumas idéias que defendia.

71 FRANCO, Elementos ..., p. 45. 